\title{
Particularidades da anestesia em felinos
}

\author{
Particularities of anesthesia in felines \\ Particularidades de la anestesia en felinos
}

Recebido: 12/04/2021 | Revisado: 20/04/2021 | Aceito: 25/04/2021 | Publicado: 10/05/2021

Luara Rodrigues Rezende

ORCID: https://orcid.org/0000-0002-8234-1110

Centro Universitário Barão de Mauá, Brasil

E-mail: luara_rr@hotmail.com

Eveline Simões Azenha Aidar

ORCID: https://orcid.org/0000-0001-7484-0799

Universidade Estadual Paulista "Júlio de Mesquita Filho", Brasil

E-mail: eveline.azenha@gmail.com

Ana Paula Gering

ORCID: https://orcid.org/0000-0001-7818-627X

Universidade Federal do Tocantins, Brasil

E-mail: geringbr@yahoo.com.br

Elda Ely Gomes de Souza

ORCID: https://orcid.org/0000-0001-5542-3930

Universidade Federal do Pará, Brasil

E-mail: eldamedvet@gmail.com

Caroline Ribeiro de Andrade

ORCID: https://orcid.org/0000-0003-0761-6652

Universidade Estadual Paulista "Júlio de Mesquita Filho", Brasil

E-mail: carolrdeandrade@hotmail.com

Bruna Brabosa de Sousa

ORCID: https://orcid.org/0000-0002-2178-4583

Universidade Federal do Tocantins, Brasil

E-mail: brunabsousa@outlook.com

Cinthian de Cássia Mendonça

ORCID: https://orcid.org/0000-0003-4883-5747

Universidade Federal do Tocantins, Brasil

E-mail: cinthianmedvet@ hotmail.com

Rafael Romeu Ferreira Diniz

ORCID: https://orcid.org/0000-0002-2277-0298

Universidade Estadual Paulista "Júlio de Mesquita Filho", Brasil

E-mail: romeumedicinavet@outlook.com

\begin{abstract}
Resumo
As complicações anestésicas parecem relativamente raras, em contraponto trabalhos recentes sugerem que há maior prevalência em gatos do que em cães. As particularidades anestésicas observadas em felinos podem estar diretamente relacionadas às maiores taxas de complicações observadas nestes animais. Aspectos importantes nesta espécie, tais como, ansiedade e estresse perianestésicos são exemplos peculiares, outras causas que podem ser elencadas como coadjuvante na ocorrência de complicações anestésicas é o monitoramento perianestésico, o papel desempenhado por doenças subjacentes assim como o uso correto de equipamentos de anestesia e da anestesia total injetável que por vezes são negligenciados pelos anestesistas. Diante disso, o trabalho objetivou revisar e discutir as principais particularidades anestésicas em felinos, possibilitando ao veterinário compreender os aspectos mais importantes da anestesia destes pacientes, evitando complicações perioperatórias associadas a doenças pré-existentes, agentes anestésicos, controle das vias aéreas, manejo e monitoramento. Esses dados podem ajudar os veterinários a cuidar do paciente sob anestesia e direcionar maior atenção à avaliação e tratamento do paciente antes, durante e após o procedimento.
\end{abstract}

Palavras-chave: Complicações anestésicas; Fatores de risco; Gatos; Mortalidade; Perioperatório.

\begin{abstract}
Anesthetic complications appear relatively rare, though recent work suggests they are more common in cats than dogs. The anesthetic particularities observed in felines may be directly related to the higher rates of complications observed in these animals. Important aspects in this species, including perianesthetic anxiety and stress, perianesthetic monitoring, the role of underlying diseases as well as the correct use of anesthesia equipment and total intravenous anesthesia, are often overlooked by anesthetists. Therefore, the study aimed to review and discuss the main anesthetic particularities in felines, enabling the veterinarian to understand the most important aspects of anesthesia in these
\end{abstract}


patients, avoiding perioperative complications associated with pre-existing diseases, anesthetic agents, airway control, management and monitoring. These data can help veterinarians to care for the patient under anesthesia and direct more attention to the assessment and treatment of the patient before, during and after the procedure.

Keywords: Anesthetic complications; Risk factors; Cats, Mortality; Perioperative.

\section{Resumen}

Las complicaciones anestésicas parecen relativamente raras, sin embargo, trabajos recientes sugieren que existe una mayor predominio en gatos que en perros. Las particularidades anestésicas observadas en felinos pueden estar directamente relacionadas a mayores tasas de complicaciones observadas en estos animales. Como aspectos peculiares a destacar en esta especie aparecen la ansiedade y el estrés perianestésico, otras causas que pueden ser destacadas como coadyuvantes en la aparición de complicaciones anestésicas son el seguimiento perianestésica, el papel desempeñado por enfermedades subyacentes así como el uso correcto de equipos de anestesia y da anestesia total inyectable, los cuales a veces son descuidados por los anestesistas. Siendo así, el trabajo tuvo por objetivo revisar y analizar las principales particularidades anestésicas en felinos, ofreciendo al veterinario la posibilidad comprender los aspectos más importantes de la anestesia en estos pacientes, evitando complicaciones perioperatorias asociadas a enfermedades preexistentes, agentes anestésicos, control de las vías respiratorias, manejo y observación. Eses datos pueden ayudar a los veterinarios a cuidar del paciente anestesiado orientando una mayor atención a la evaluación y tratamiento del paciente a lo largo de todo el procedimiento.

Palabras clave: Complicaciones anestésicas; Factores de riesgo; Gatos; Mortalidad; Perioperatorio.

\section{Introdução}

Diante da menor necessidade de cuidados que os gatos requerem, o número de gatos de estimação vem apresentando aumento na maioria dos países desenvolvidos (AVMA, 2018). Apesar desse aumento, o número de gatos domésticos ainda permanece menor que o número de cães (Toribio et al., 2009; AVMA, 2018). No Brasil, o aumento na população de gatos pode ser associado principalmente à população residente em apartamentos pequenos, com restrição de espaço para alojar os pets (Serafini et al., 2008).

De maneira geral, os tutores de gatos têm menor propensão a obter cuidados veterinários do que os tutores de cães (Rodan et al., 2011; AVMA, 2018), entre os motivos, a dificuldade do transporte até a clínica veterinária, o manuseio e o estresse do animal estão entre os relatados pelo proprietário (Rodan et al., 2011). No entanto, em estudo direcionado apenas à população de felinos domésticos, apenas 5,8\% dos gatos nunca haviam visitado uma clínica veterinária, e o período médio da última visita dos 94,2\% restantes foi de 1,5 anos (Toribio et al., 2009), mostrando crescimento da procura por atendimento específico para esses pacientes.

A anestesia é um aspecto importante da prática veterinária felina, permitindo a contenção, analgesia, procedimentos diagnósticos e cirúrgicos destes pacientes.

Para manuseio amigável do paciente felino, a contenção química pode ser necessária, visando aumentar a segurança e reduzir o estresse do gato, do tutor e da equipe de atendimento (Rodan et al., 2011).

Dados sobre prática anestésica em pequenos animais, mostram uma média alta de procedimentos anestésicos desses pacientes, com dados de 10 gatos (mínimo 1, máximo 40) submetidos à anestesia semanalmente (Sano et al., 2017).

Embora morte relacionada à procedimentos anestésicos, em gatos, tenham diminuído nos últimos anos, os gatos submetidos à anestesia continuam a ter uma taxa de mortalidade aumentada em comparação aos cães (Dyson et al., 1998; Brodbelt, 2010; Pypendop \& Ilkiw, 2015; Robertson et al., 2018).

Vários fatores de risco foram associados a maior taxa de mortalidade em gatos, entre eles, o estado de saúde do paciente de acordo com a classificação ASA-PS (American Society of Anesthesiologists Physical Status Classification), excesso de peso, aumento da urgência e complexidade do procedimento, intubação endotraqueal e fluidoterapia (Brodbelt, 2010; Pypendop \& Ilkiw, 2015). O tamanho relativamente pequeno dos gatos e a maior relação superfície/volume, predispõe a hipotermia e ao uso de dosagem excessiva de fármacos nesses pacientes (Brodbelt et al., 2007). Além disso, a pequena via 
respiratória, laringe sensível e responsiva a estimulação mecânica, predispõe os gatos a complicações nas vias aéreas superiores (Pascoe \& Pypendop, 2015).

Perante o exposto, o trabalho objetiva através de levantamento bibliográfico apresentar e discutir as particularidades anestésicas em felinos, possibilitando ao veterinário compreender os aspectos mais importantes da anestesia felina, evitando complicações perioperatórias associadas ao monitoramento, controle das vias aéreas, resposta a agentes anestésicos e doenças pré-existentes.

\section{Metodologia}

A metodologia de pesquisa selecionada para este trabalho foi a revisão de literatura. A produção deste artigo contou com a pesquisas bibliográfica por intermédio da metodologia de abordagem qualitativa com o objetivo de reunir e explicar informações sobre as particularidades da anestesia em felinos (Pereira et al., 2018).

O processo de seleção, classificação e análise das obras foi realizado pelos autores deste estudo. A pesquisa teve como base artigos científicos publicados em revistas e jornais nacionais e internacionais. As plataformas de artigos científicos utilizadas para a pesquisa foram: Elsevier, Library, PubMed, ResearchGate, SciELO e ScienceDirect. Para pesquisa física, foram utilizados livros de Anestesiologia Veterinária e Medicina Interna de Gatos oriundos de acervo pessoal.

Devido a relevância em se buscar informações amplas sobre o assunto, optou-se pela escolha de artigos publicados desde 2002 até o ano de 2021, com exceção de seis artigos que tiveram como ano de publicação o período de 1984 até 1998, devido a importância das informações que não foram encontradas em trabalhos mais recentes.

Os termos de buscas utilizados foram "anesthesia in felines", "preoperative examinations in felines", "anesthetic complications in felines", "chronic diseases in felines". Geralmente, ao se encontrar um artigo, as plataformas sugeriam outros artigos com o tema aproximado e este também era escolhido para leitura e avaliação. Alguns artigos foram escolhidos com base no referencial bibliográfico de outros trabalhos publicados, visto que apresentavam informações e conteúdos importantes para o tema.

\section{Riscos Relacionados a Procedimentos Anestésicos em Felinos}

Mundialmente, o aumento da educação veterinária em anestesia, a disponibilidade de treinamento técnico mais específico na área de monitoramento anestésico e educação continuada em terapia intensiva e anestesia tem impactado sobre a morbidade e mortalidade anestésica em pequenos animais (Dyson et al., 1998; Grubb et al., 2020).

Os estudos avaliando mortalidade anestésica em pequenos animais vem mostrando que os riscos moderadamente altos de mortalidade em gatos parecem estar diminuindo ao longo do tempo (Dyson et al., 1998; Sano et al., 2017), contudo, ainda há uma tendência ao maior risco de morte em gatos comparativamente aos cães (Brodbelt et al., 2007; Brodbelt, 2010; Pypendop \& Ilkiw, 2015).

Os primeiros estudos avaliando fatores de risco para morte relacionada à procedimentos anestésicos em gatos, associaram as complicações a classificação ASA 3, 4 ou 5 destes pacientes (Dyson et al., 1998; Hosgood \& Scholl, 2002); uso de diazepam e intubação (Dyson et al., 1998). A parada cardíaca foi associada à classificação ASA 3, 4 ou 5 e a presença/ausência de anestesista durante todo o procedimento anestésico (Dyson et al., 1998).

O status ASA foi significativamente associado ao risco de complicações perianestéticas graves, mesmo quando contabilizando outros efeitos, como a duração do anestésico. Gatos que receberam classificação ASA igual ou superior a 3 apresentaram risco quase quatro vezes maior de complicações perianestésicas (Hosgood \& Scholl, 2002). 
É provável que isso reflita a importância da capacidade de avaliar e estabilizar pacientes no pré-operatório e também devido à tendência de procedimentos urgentes serem apresentados fora do horário normal de trabalho, sujeitos a fadiga da equipe veterinária (Brodbelt, 2010).

Em gatos, o período pós-operatório apresenta as maiores taxas de óbito relacionados com anestesia (Dyson et al., 1998; Brodbelt et al., 2007). No estudo de Brodbelt e colaboradores (2007), mais de 60\% dos gatos vieram a óbito durante esse período evidenciando a necessidade de maior cuidado e vigilância no pós-operatório precoce.

Não foram encontradas associações significativas da idade e com complicações anestésicas (Hosgood \& Scholl, 2002; Brodbelt et al., 2007). Entretanto, pacientes idosos podem ser mais suscetíveis aos efeitos depressivos dos anestésicos, à hipotermia por mecanismos termorregulatórios prejudicados e à recuperação prolongada devido às tendências de redução função metabólica e hipotermia (Pypendop \& Ilkiw, 2015).

Diante dos riscos associados aos procedimentos anestésicos em gatos, a Associação Americana de Profissionais Especialistas em Felinos (AAFP) publicaram diretrizes para anestesia felina visando evitar complicações perioperatórias associadas ao monitoramento, controle das vias aéreas, fluidoterapia e recuperação, e discutir outros aspectos importantes, incluindo ansiedade e estresse perianestésicos, monitoramento perianestésico, o papel de doenças subjacentes assim como o uso correto de equipamentos de anestesia e da anestesia total injetável nesses pacientes (Robertson et al., 2018).

\section{Cuidados e Particularidades Relacionadas ao Período Pré-anestésico}

\subsection{Manuseio e Comportamento Felino}

O comportamento agressivo é uma queixa comum dos proprietários de felinos, mordidas destes pacientes em humanos podem, potencialmente, resultar em doenças e danos sérios (Horwitz \& Pike, 2018). Adicionalmente, como muitos gatos estão estressados no momento da apresentação inicial, o exame físico e os resultados laboratoriais podem refletir isso, dificultando a interpretação; por exemplo, a glicose no sangue, a frequência cardíaca e a pressão sanguínea podem estar elevadas, sem necessariamente correlacionar-se a uma doença pré-existente (Robertson et al., 2018).

Um temperamento agressivo pode também limitar a avaliação pré-anestésica ou impossibilitar o exame clínico antes da sedação. Isso pode prejudicar a capacidade de detectar anormalidades no paciente felino e aumentar o risco anestésico. Pacientes ansiosos geralmente requerem altas doses de sedativos ou tranquilizantes, o que pode causar depressão respiratória e cardiovascular (Grubb et al., 2020)

Numerosas condições médicas e ambientais podem provocar respostas agressivas nesses pacientes (Kushner, 2010a). Dessa forma, o gato agressivo representa um desafio para a realização de tarefas não invasivas sem boa contenção química (Pypendop \& Ilkiw, 2015).

Apesar da inexistência de um sistema de pontuação da dor validado para uso em gatos, as reações agressivas podem estar associadas ao quadro de dor (Pascoe \& Pypendop, 2015).

Para abordar a importância de oferecer o melhor atendimento possível aos gatos, a Associação Americana de Profissionais Especialistas em Felinos e a Sociedade Internacional de Medicina Felina, desenvolveram diretrizes específicas para o manuseio amigável dos felinos (Rodan et al., 2011). Entre as diretrizes, a contenção química preventiva é a recomendada.

Rotineiramente gatos hígidos podem apresentar condições de natureza aguda em que é necessária sedação ou anestesia para realização de procedimento diagnósticos ou terapêuticos (Kushner, 2010b).

O gato pode demonstrar medo, ansiedade e estresse de várias maneiras, incluindo agressão, ocultação, fuga ou congelamento. Quando qualquer um desses comportamentos é exibido, o paciente pode se beneficiar da medicação administrada em casa para reduzir a ansiedade e o medo antes de viajar para o hospital (Grubb et al., 2020). 
O aumento da liberação de catecolaminas em gatos com medo ou estressados leva a taquicardia, hipertensão arterial sistêmica e / ou taquipneia, fatores que podem aumentar os riscos associados à anestesia. Diante disso, ressalta-se a importância do manuseio respeitoso e do uso prévio de gabapentina ou outra contenção química, quando necessário (Robertson et al., 2018).

Sedação leve a moderada é recomendada para facilitar exames radiográficos, ultrassonográficos ou para aplicação de curativos ou talas; sedação intensa fica recomendada para procedimentos como cateterização uretral para desobstrução uretral, punção biópsia por agulha fina, punção de medula óssea, toracocentese e etc. (Kushner, 2010a).

Outro desafio do clínico em relação ao paciente felino, é a resposta a agentes sedativos e analgésicos. A capacidade limitada do gato em eliminar medicamentos via glucoronidação e a suscetibilidade de glóbulos vermelhos felinos a lesões oxidativas podem influenciar sua resposta a alguns medicamentos, como benzodiazepínicos e propofol (Kushner, 2010a).

\subsection{Jejum alimentar}

O objetivo do jejum pré-operatório é reduzir o volume do conteúdo estomacal prevenindo o refluxo gastroesofágico (RGE), regurgitação e aspiração. Tradicionalmente o jejum alimentar de 6 a 12 horas antes do procedimento anestésico é recomendado, contudo, tal recomendação não possui embasamento em evidências (Garcia et al., 2017). O RGE e suas sequelas associadas são causas de morbidade e mortalidade potencial em várias espécies, incluindo os gatos (Galatos \& Raptopoulos, 1995; Garcia et al., 2017).

O RGE durante a anestesia é um fenômeno comum, em gatos tem sido associado a lesões graves na parede esofágica, incluindo formação de estenose e perfuração esofágica (Adami et al., 2011).

A patogênese da esofagite relacionada ao RGE possui caráter multifatorial. Prolongar o jejum pré-operatório leva a um aumento da incidência de refluxo e aumento da acidez gástrica (Galatos \& Raptopoulos, 1995). Adicionalmente, a anestesia pode resultar em incompetência transitória do esfíncter inferior do esôfago, principalmente devido à administração de agentes anestésicos (Hashim \& Waterman, 1991).

Em estudo avaliando a influência dos agentes de indução anestésica no tônus do esfíncter esofágico inferior, todos os agentes avaliados, incluindo o propofol, levaram a redução do tônus do esfíncter esofágico inferior, porém, a redução foi menor com a cetamina (Hashim \& Waterman, 1991). O uso de diazepam na medicação pré-anestésica também foi associada a menos episódios de RGE (Galatos \& Raptopoulos, 1995).

Os longos períodos de jejum não garantem que o estômago de um gato esteja vazio. Estresse, tamanho da refeição e falta de umidade na dieta podem retardar o esvaziamento gástrico. Portanto, o anestesista deve estar sempre preparado para o vômito perioperatório (Robertson et al., 2018).

Embora não haja dados em gatos, tempos de jejum mais curtos (3 a 4 horas) (Galatos \& Raptopoulos, 1995), associado ao fornecimento de uma última refeição composta de alimento úmido antes da anestesia, podem ser adotados a critério do médico veterinário; a água deve estar disponível até o momento da pré-medicação (Robertson et al., 2018).

Outra ferramenta que pode ser utilizada para reduzir a morbidade do RGE em gatos é o uso de omeprazol no período pré-operatório (Garcia et al., 2017). A administração pré-anestésica de 2 doses de omeprazol (de 18 a 24 horas e 4 horas antes do procedimento) na dose de $1,45-2,20 \mathrm{mg} / \mathrm{kg}$ em gatos foi associada a um aumento significativo do $\mathrm{pH}$ gástrico e esofágico em 24 horas, isso resultaria na redução dos efeitos deletérios do conteúdo gástrico, caso o RGE ocorra durante a anestesia. 


\subsection{Comorbidades}

\subsubsection{Cardiomiopatia hipertrófica}

A cardiomiopatia hipertrófica (CMH) é uma das cardiopatias mais comuns que acometem os felinos (Gil-Ortuño et al., 2020). Uma boa avaliação clínica por meio da auscultação cardíaca, respiratória, a observação da coloração das mucosas e os exames complementares como: hematologia, bioquímica completa, radiografias torácicas, eletrocardiograma e ultrassonografia cardíaca são recomendados antes de sedar ou anestesiar um gato com CMH (Grubb et al., 2020).

A anestesia em gatos com $\mathrm{CMH}$ é direcionada à otimização do preenchimento diastólico, mantendo a frequência cardíaca relativamente baixa e evitando medicamentos que podem aumentar a contratilidade cardíaca. Adicionalmente, a otimização da pré-carga e do enchimento ventricular pode ser útil, enquanto a redução da pós-carga pode piorar a obstrução e diminuições acentuadas nas pressões arteriais são pouco toleradas por estes pacientes (Perkowski \& Oyama, 2015).

Infelizmente, a maioria dos agentes anestésicos comumente usados não é ideal quando se tenta atingir esses objetivos hemodinâmicos em gatos com obstrução da via de sáida do ventrículo esquerdo (VSVE). Fármacos como acepromazina, cetamina e isoflurano podem piorar o quadro a curto prazo (Lamont et al., 2002).

Comumente, os gatos com CMH são pré-medicados com um agonista de receptor $\mu$-opioide, como a oximorfina, a hidromorfina ou a metadona. $\mathrm{O}$ glicopirrolato pode ser adicionado se a frequência cardíaca estiver excessivamente baixa. $\mathrm{O}$ uso do agonista $\alpha 2$-adrenérgico medetomidina mostrou reduzir a obstrução do trato de saída do ventrículo esquerdo em gatos com hipertrofia muscular esquerda (Pypendop \& Ilkiw, 2015).

A medetomidina, como outros agonistas dos receptores $\alpha 2$-adrenérgicos, possui um espectro único de atividade. Induz sedação, analgesia, tem efeito ansiolítico, promove relaxamento muscular, e seus efeitos são completamente reversíveis com o antagonista específico atipamezole (Lamont et al., 2002). Esse agonista do receptor $\alpha 2$ - adrenérgico, causa vasoconstrição e aumento da resistência vascular sistêmica, ambos potencialmente desejáveis com a CMH com obstrução da VSVE. No entanto, a função sistólica deve ser avaliada cuidadosamente antes da administração de agonistas do receptor $\alpha 2$ - adrenérgico (Perkowski \& Oyama, 2015).

$\mathrm{O}$ uso de agonistas $\alpha 2$-adrenérgicos em gatos com CMH é controverso (Robertson et al., 2018). Lamont e colaboradores (2002) sugere uma redução benéfica na obstrução à saída em gatos com obstrução da VSVE. Entretanto, uma preocupação é que o aumento da pós-carga associado à administração de agonista $\alpha 2$-adrenérgico ou ao estresse diminua o débito cardíaco nestes pacientes, além disso, a dexmedetomidina isolada ou combinada com outras drogas causa alterações no tamanho e na função atrial e ventricular (Robertson et al., 2018). Diante disso, o benefício de reduzir o estresse do paciente, prevenir taquicardia e reduzir as necessidades de anestésicos inalantes pode superar os riscos potenciais associados a doses baixas de medicamentos agonistas $\alpha 2$-adrenérgicos (Robertson et al., 2018).

Doses baixas de opioides, como fentanil, metadona ou oximorfona pode ser administrada como parte da técnica de indução. A indução com etomidato, que tem um efeito mínimo na contratilidade cardiovascular, e um tranquilizante benzodiazepínico, como midazolam ou diazepam, são frequentemente usados quando o acesso venoso está disponível (Perkowski \& Oyama, 2015).

A indução da anestesia é melhor realizada empregando-se um agente injetável, pois a indução com agentes inalatórios provoca agitação e liberação de catecolaminas. Etomidato e um benzodiazepínico são preferíveis, particularmente em casos graves. Nos casos brandos a moderados, o propofol, de forma isolada ou associado a um benzodiazepínico, é uma alternativa aceitável, contudo, leva à vasodilatação sistêmica e diminuição da pós-carga (Pypendop \& Ilkiw, 2015).

A utilização do etomidado é normalmente indicada para a indução anestésica em pacientes com alto risco de hipotensão e alterações cardíacas uma vez que ele confere melhor estabilidade hemodinâmica sob o sistema cardiovascular, a ligação do etomidato às proteínas plasmáticas é alta, contudo, menor do que a do propofol (Kim et al., 2020). 
A atividade inotrópica positiva pode potencialmente aumentar a obstrução dinâmica da via de saída, além do consumo de oxigênio no miocárdio. Tiopental e agentes dissociativos (quetamina, tiletamina) devem ser evitados, devido a liberação descontrolada de catecolaminas, taquicardia e aumento da contratilidade miocárdica e consumo de oxigênio causada por estes fármacos (Perkowski \& Oyama, 2015).

A manutenção anestésica é feita com isoflurano ou, preferencialmente, sevoflurano no oxigênio. Isso porque, acreditase que ele reduza a resistência vascular sistêmica a uma extensão menor que o isoflurano (Pypendop \& Ilkiw, 2015).

Gatos que recebem diuréticos de alça podem ter desequilíbrios eletrolíticos que devem ser corrigidos antes da anestesia. Em casos de arritmias e edema pulmonar identificados previamente, o tratamento deve ser realizado antes da anestesia, quando possível. Medicações administradas cronicamente, como bloqueadores beta-adrenérgicos e bloqueadores dos canais de cálcio devem ser administradas como de hábito no dia da anestesia (Pypendop \& Ilkiw, 2015).

\subsubsection{Hipertireoidismo}

O hipertireoidismo é um distúrbio multissistêmico decorrente de níveis excessivos dos hormônios tireóideos T4 e T3; é considerado o distúrbio endócrino mais comum em gatos. Devido a interação dos hormônios tireoidianos com o sistema nervoso central, em particular, o tônus do sistema nervoso simpático encontra-se aumentado, o que resulta em hiperexcitabilidade ou nervosismo, alterações comportamentais, tremores e taquicardia (Pypendop \& Ilkiw, 2015).

Como o hipertireoidismo afeta vários sistemas, é desejável obter um estado eutireoideo antes de um procedimento anestésico eletivo iniciando a medicação antitireoidiana 2 a 3 semanas antes do procedimento e verificando os níveis totais de tiroxina ao final desse período (Robertson et al., 2018).

Se não for adequadamente preparada previamente, a anestesia pode causar sérias complicações no gato hipertireoidiano, como arritmias ventriculares e morte aguda. A administração pré-operatória de um medicamento antitireoidiano até que as concentrações séricas do hormônio tireoidiano sejam reduzidas ao normal ajudam a reduzir os riscos anestésicos associados ao hipertireoidismo (Peterson et al., 1984).

Caso seja necessária anestesia de emergência por problema não relacionado ao hipertireoidismo em gatos com taquicardia significativa (> 200 batimentos por minuto - bpm), um beta bloqueador como o atenolol, a $1 \mathrm{mg} / \mathrm{kg}$, via oral a cada 12 ou 24 horas, pode ser iniciado antes da anestesia. No entanto, se durante a anestesia a frequência cardíaca ficar acima de 220 bpm com uma profundidade anestésica adequada, inicie uma infusão contínua de esmolol com uma dose de carga de 0,10,5 mg/kg via intravenosa por 1 minuto, seguida por infusão contínua de 100-200 $\mu \mathrm{g} / \mathrm{kg} / \mathrm{minuto}$ (Robertson et al., 2018).

Em geral, um opioide é utilizado na medicação pré-anestésica, podendo ser associada a uma dose baixa de medetomidina ou dexmedetomidina, a fim de se obter sedação e diminuir o tônus simpático (Pypendop \& Ilkiw, 2015).

A indução intravenosa apresenta melhores resultados em comparação com a indução com máscara ou com câmara. Em gatos sem insuficiência cardíaca, um tiobarbiturato pode ser adequado. O diazepam pode ser administrado associado aos tiobarbitúricos, a fim de reduzir a dose deste e prolongar levemente o tempo de ação. Contudo, o tiopental é o agente de indução com mais efeito arritmogênico. O propofol ou o etomidato são boas alternativas. Em particular, em gatos com insuficiência cardíaca ou disritmias, o etomidato associado a um benzodiazepínico provavelmente terá efeitos mínimos sobre a função cardiovascular e respiratória. Geralmente, os agentes dissociativos quetamina e tiletamina são evitados por causa da estimulação simpática que produzem (Peterson et al., 1984; Pypendop \& Ilkiw, 2015).

Os objetivos durante a manutenção da anestesia consistem em evitar a administração de fármacos que sensibilizam o coração a catecolaminas e proporcionar certo nível de anestesia ou usar uma técnica que evite respostas exageradas a estimulação nociva. O isoflurano ou o sevoflurano são boas escolhas (Pypendop \& Ilkiw, 2015). 
Durante o período anestésico, é essencial monitorar cuidadosamente o nível anestésico e a função cardíaca. Arritmias ventriculares são comuns, principalmente em gatos que não atingem função tireoidiana adequada antes da cirurgia (Peterson et al., 1984).

\subsubsection{Doença renal}

A doença renal crônica (DRC) em gatos é um processo prolongado marcado pela perda irreversível da função renal, geralmente sem uma causa identificável, que tem sido cada vez mais diagnosticada, principalmente em gatos idosos (Marino et al., 2014).

Apesar da tendência de empregar os termos "doença renal crônica" e "insuficiência renal crônica" (DRC/IRC) como uma entidade única, convém ter em mente que esses termos se referem a um conjunto de sinais clínicos que podem ser consequência de muitas etiologias e entidades patológicas diferentes (Pypendop \& Ilkiw, 2015).

Não existe um fármaco anestésico ou uma combinação destes que seja melhor para a doença renal; o mais importante nesses pacientes é a manutenção da pressão sanguínea e da perfusão renal (Bednarski et al., 2011).

A correção das anormalidades de fluidos e eletrólitos no paciente doente renal, deve ser realizado o máximo possível antes da anestesia, avaliando o risco benefício da necessidade de correção de fluido pré-anestésico e a urgência cirúrgica; em pacientes urêmicos, haverá grandes benefícios com a administração de fluidos pré-anestésicos. Além disso, é importante ter um planejamento do uso de fluidos em uma emergência relacionada à anestesia em pacientes com doença renal oligúrica ou poliúrica (Davis et al., 2013).

A fluidoterapia pré-anestésica pode ser útil para restauração da normovolemia e da hidratação; o estadiamento da Sociedade Internacional de Interesse Renal (IRIS) deve ser utilizado para orientar a terapia (Robertson et al., 2018).

Davis et al. (2013) sugerem a administração intravenosa de uma solução eletrolítica balanceada por período igual ou superior a 4 horas na dose de $3-5 \mathrm{ml} / \mathrm{kg} / \mathrm{h}$ ou baseada em uma dose de manutenção diária calculada utilizando a fórmula: $80 \mathrm{x}$ peso corporal $(\mathrm{kg})^{0,75}$ por 24 horas, antes da anestesia em gatos com doença renal em estágio IRIS $\geqslant 3$ (estágio 3: pacientes com azotemia moderada, creatinina 2,9-5,0 $\mu \mathrm{mol} / \mathrm{L}$; estágio 4: pacientes com azotemia severa, creatinina $\geq 5,0 \mu \mathrm{mol} / \mathrm{L}$ ).

Para gatos em tratamento que recebam enalapril, a descontinuação de 24 a 48 horas antes da anestesia pode reduzir o risco de hipotensão intraoperatória (Robertson et al., 2018).

A diurese em pacientes moderadamente ou severamente azotêmicos antes da indução anestésica pode ser justificada em alguns casos. Isso porque a diurese induzida por manitol pode levar ao aumento da perfusão medular renal associada. Vasopressores e inotrópicos têm sido recomendados, mas estritamente para manter o débito cardíaco; não há consenso sobre a contribuição destes para o aumento da perfusão ou proteção renal (Bednarski et al., 2011).

O monitoramento e o gerenciamento da pressão arterial são essenciais no período perianestésico; a fluidoterapia intravenosa deve ser mantida até que o paciente possa comer e beber (Robertson et al., 2018). A fluidoterapia no período pósoperatório deve ser feita conforme as necessidades do paciente (Bednarski et al., 2011).

\subsubsection{Diabetes mellitus}

Quando gatos com diabetes mellitus (DM) necessitam de anestesia para atendimento médico e procedimentos cirúrgicos, estes procedimentos geralmente não estão diretamente relacionados ao DM (Adams, Figueiredo \& Graves, 2015).

Assim como em outras comorbidades, o ideal é que os pacientes diabéticos sejam bem regulados antes de qualquer procedimento anestésico (Robertson et al., 2018). Isso porque pacientes com diabetes não regulado, podem ter uma flutuação acentuada da concentração de glicose sanguínea. Além disso, em pacientes desregulados, a administração de insulina antes da anestesia pode resultar em concentrações perioperatórias imprevisíveis de glicose no sangue (Adams et al., 2015). 
A realização de procedimentos anestésicos nesses pacientes, devem ser programados para serem o primeiro caso anestésico do dia, para que possam receber alta no mesmo dia, a fim de que a alimentação normal e o regime de insulina sejam retomados sem interrupção (Robertson et al., 2018).

Embora as recomendações para o jejum pré-operatório possam variar, em geral no dia anterior à cirurgia os animais devem ser alimentados normalmente e a insulina administrada de acordo com o regime usual. Na manhã da cirurgia, a glicose sanguínea deve ser mensurada antes da administração de insulina, sendo a administração de acordo com a glicemia do paciente (Adams et al., 2015).

De acordo com as diretrizes publicadas pela AAFP (Robertson et al., 2018), necessidade de administração ou não de insulina no período perioperatório em felinos é baseado nos valores de glicose no sangue anteriores ao procedimento. Assim, as seguintes recomendações são feitas:

- $\quad$ Se a glicose no sangue for $<8 \mathrm{mmol} / \mathrm{L}$ ( $<145 \mathrm{mg} / \mathrm{dl}$ ), não é necessária insulina;

- Valores entre 8 - 15 mmol / L (145 a $270 \mathrm{mg} / \mathrm{dl}$ ), metade da dose regular de insulina do gato é administrada;

- Valores maiores que $15 \mathrm{mmol} / \mathrm{L}$ (> $270 \mathrm{mg} / \mathrm{dl}$ ) é administrada a dose completa de insulina.

De maneira geral, nos procedimentos anestésico e cirúrgico do gato diabético, é preciso estar preparado para tratar um amplo espectro de problemas, que variam de hipoglicemia a cetoacidose e desidratação graves. O objetivo do manejo diabético não é alcançar a homeostase metabólica perfeita, mas evitar profundas anormalidades nos fluidos corporais, eletrólitos, equilíbrio ácido-base e na glicemia durante o período perioperatório (Peterson et al., 1984).

A escolha dos agentes pré-anestésicos e anestésicos tem pouco impacto no controle intraoperatório da glicemia. Embora os agentes anestésicos comumente usados possam afetar o metabolismo da glicose, sua contribuição direta para alteração nas concentrações de glicose no sangue é discreta (Peterson et al., 1984).

Não existem contra indicações absolutas de fármacos anestésicos em pacientes diabéticos. No entanto, medicamentos com rápida eliminação ou que podem ser revertidos, permitem que o paciente diabético retome um esquema normal de alimentação e insulina de forma mais precoce após a anestesia (Adams et al., 2015).

Monitoramento pré e intraoperatório (a cada 30 minutos) de glicose no sangue é recomendada (Peterson et al., 1984; Adams et al., 2015; Robertson et al., 2018). A verificação dos níveis de glicose na recuperação pode ser necessária, principalmente se a insulina tiver sido administrada durante a anestesia e se o paciente não estiver comendo. Nesses casos, Se a glicose no sangue cair abaixo de $3 \mathrm{mmol} / \mathrm{L}$ ( $54 \mathrm{mg} / \mathrm{dl}$ ), 0,25 a 0,5 g / $\mathrm{kg}$ de dextrose é administrado em bolus por via IV; e se ocorrer hiperglicemia grave (> $30 \mathrm{mmol} / \mathrm{L}, 540 \mathrm{mg} / \mathrm{dl}$ ), a dose normal de insulina do gato é administrada. Caso as concentrações de glicose no sangue permaneçam entre esses extremos, soluções eletrolíticas balanceadas com ou sem dextrose (2,5\% a 5\%) podem ser usadas com base nos resultados do monitoramento (Robertson et al., 2018).

\subsubsection{Asma ou doença das vias aéreas inferiores}

Essencialmente, define-se asma como a broncoconstrição reversível. O gato é a única espécie animal que comumente desenvolve uma síndrome de asma semelhante àquela comum em humanos, com inflamação eosinofílica de vias respiratórias, broncoconstrição espontânea e remodelamento de vias respiratórias (Quimby \& Lappin, 2015).

Os animais com doenças das vias aéreas inferiores, incluindo a asma felina, podem necessitar de anestesia para permitir a coleta de amostras diagnósticas ou para a execução de procedimentos não relacionados à doença pulmonar (Mcdonell \& Kerr, 2015). 
As complicações relacionadas à sedação e / ou anestesia geral podem aumentar significativamente em gatos com doenças das vias aéreas inferiores. Embora não existam protocolos anestésicos específicos na medicina veterinária para asma felina, como existem na medicina humana, as recomendações para anestesia de pequenos animais com doença do trato respiratório inferior devem ser seguidas (Mcdonell \& Kerr, 2015; Robertson et al., 2018).

No momento da MPA, a inclusão de um anticolinérgico pode ser vantajosa devido ao seu efeito broncodilatador, embora seu uso seja controverso. A acepromazina também pode beneficiar esses pacientes devido aos seus efeitos na inibição da liberação de histamina, por outro lado, os opioides com potencial para aumentar a liberação de histamina, como a meperidina IV, devem ser evitados (Mcdonell \& Kerr, 2015).

É recomendada a indução anestésica com quetamina ou propofol, devido aos efeitos broncodilatadores relativos destes fármacos. Adicionalmente, os anestésicos dissociativos podem agir como simpatomiméticos na maioria dos animais, resultando em aumento no diâmetro das vias aéreas inferiores por meio da ativação indireta dos receptores $\beta 2$ - adrenérgicos (Mcdonell \& Kerr, 2015).

Durante a manutenção anestésica, os pacientes com doença do trato respiratório inferior, podem apresentar quadros mais graves de ventilação inadequada, resultando em comprometimento da oxigenação, exigindo a instituição de suporte ventilatório (Mcdonell \& Kerr, 2015).

Esses pacientes podem descompensar rapidamente, por isso, a equipe veterinária deve abordar esses casos de maneira proativa e ter todo o equipamento e suprimentos potencialmente necessários disponíveis antes de iniciar a sedação. Diante disso, a AAFP estabeleceu diretrizes de conduta durante a realização de sedação ou anestesia de gatos com asma felina (Robertson et al., 2018). Sendo as principais recomendações:

- Manter o paciente em uso dos medicamentos para tratamento da asma até a manhã da anestesia, inclusive;

- Utilizar sedação pré-anestésica (por exemplo, gabapentina, butorfanol, acepromazina) para reduzir o estresse desses pacientes;

- Se for possível, pré-oxigenar o paciente com oxigênio a 100\% por 3-5 minutos com máscara facial ou técnica de escoamento (antes da indução anestésica);

- Utilizar cateterização endovenosa em todos os pacientes, inclusive em procedimentos de sedação leve;

- Estar sempre preparado para intubar (escolha e separação dos materiais necessários);

- Não intubar até que o gato esteja a uma profundidade adequada da anestesia; ou, alternativamente, considere usar uma máscara laríngea;

- Monitorar a saturação de oxigênio da hemoglobina no sangue arterial (Spo2) e CO2 expirado (ETCo2); e fornecer suplementação de oxigênio continuada na recuperação, juntamente com a observação cuidadosa do paciente.

Nos procedimentos broncoscopia e a lavagem broncoalveolar, o uso prévio de terbutalina $(0,01 \mathrm{mg} / \mathrm{kg}$ de SC) deve ser considerado ao anestesiar gatos asmáticos, visando reduzir as complicações do procedimento; o início da ação após a administração SC é de 15 a 30 minutos (Robertson et al., 2018).

\subsubsection{Obesidade}

A obesidade é uma das condições mais prevalentes em gatos domesticados mundialmente. Dados epidemiológicos sugerem que alimentos ricos em gorduras desempenham papel mais importante na obesidade do que aqueles ricos em carboidratos (Murphy et al., 2015). 
Essa condição pode afetar os parâmetros farmacocinéticos dos medicamentos, como volume de distribuição, biodisponibilidade e depuração. Diante disso, os medicamentos anestésicos e as dosagens utilizadas devem ser baseados no peso corporal ideal do gato (Robertson et al., 2018).

Alguns estudos correlacionaram o aumento da taxa de mortalidade associada a procedimentos anestésicos em felinos, com a obesidade destes pacientes (Brodbelt et al., 2007; Brodbelt, 2010). Em um dos estudos, gatos com peso acima de 6 kg tinham quase três vezes mais chances de morrer durante o procedimento em comparação aos gatos com peso entre 2 e $6 \mathrm{~kg}$ (Brodbelt et al., 2007).

A obesidade pode contribuir para complicações perioperatórias por meio do aumento do potencial de comprometimento respiratório, reservas cardiovasculares reduzidas e recuperações mais lentas após anestesia inalatória (Brodbelt et al., 2007).

A principal recomendação anestésica para esses pacientes é a pré-oxigenação usando uma máscara facial ou a técnica de escoamento, visando prolongar o tempo de dessaturação, especialmente em obesos raças braquicefálicas. Além disso, esses gatos precisam ter seu status de oxigenação monitorado de perto durante o período de recuperação e podem exigir suplementação de oxigênio no pós-operatório devido à hipoventilação (Robertson et al., 2018).

\subsubsection{Obstrução uretral}

A obstrução uretral é um distúrbio clínico comum em felinos, embora não existam dados sobre a prevalência na população geral, é diagnosticada em grande porcentagem dos gatos com doença do trato urinário inferior (DTUIF) atendidos em hospitais escola, assim como em serviços de emergência veterinária (Scherk, 2015).

Encontrada quase que exclusivamente em pacientes do sexo masculino. A obstrução uretral aguda pode ser fatal e induzir insuficiência renal aguda (Pypendop \& Ilkiw, 2015).

Pacientes com obstrução uretral geralmente apresentam anormalidades metabólicas e desequilíbrio ácido-base. Estes incluem hipercalemia, azotemia, acidemia, hiperfosfatemia, hiperglicemia, hipocalcemia, hiponatremia e hipocloremia; sendo as duas última frequentemente associadas ao uroabdômen decorrente de ruptura vesical ou uretral (Clark-Price \& Grauer, 2015).

Invariavelmente, os gatos com obstrução uretral devem ser atendidos de forma emergencial. Embora a maioria dos pacientes esteja estável à apresentação, $10 \%$ ou mais exibe comprometimento fisiológico importante. Em particular, os gatos que estiveram obstruídos por 24 horas ou podem apresentar quadros clínicos graves (Scherk, 2015).

Embora um dos objetivos da terapia em gatos obstruídos seja restaurar o fluxo de urina, essa manobra de forma isolada, sem correção da desidratação e das anormalidades eletrolíticas parece estar associado a maus resultados (Robertson et al., 2018).

A hipercalemia é a anormalidade mais importante associada à obstrução completa, podendo causar alterações fatais na condução cardíaca. Em geral, os primeiros sinais clínicos são fraqueza, ausência de reflexos e outra disfunção neuromuscular, evoluindo para paralisia muscular e respiratória (Pypendop \& Ilkiw, 2015).

O potássio causa depressão progressiva da excitabilidade e da velocidade de condução. Anormalidades no ECG são comumente observadas com concentrações de potássio superiores a $7 \mathrm{mEq} / \mathrm{L}$, entre elas: pico da onda T, diminuição da amplitude e do alargamento da onda P, prolongação do intervalo P-R, desaparecimento, com o passar do tempo, da onda $\mathrm{P}$, alargamento do complexo QRS e intervalos RR irregulares e ausência de complexos QRS do tipo onda em forma de seno (Clark-Price \& Grauer, 2015).

A identificação e o tratamento imediatos da hipercalemia são críticos. Ocasionalmente, a exposição de gatos hiperpotassêmicos a agentes anestésicos é capaz de agravar a depressão cardiovascular e resultar em parada cardíaca. Uma 
parte essencial da preparação pré anestésica consiste na terapia direta para a normalização da concentração de potássio sérico antes da administração de agentes anestésicos (Pypendop \& Ilkiw, 2015). Segundo as diretrizes publicadas por Robertson e colaboradores (2018) um ou mais dos seguintes tratamentos deve ser instituído:

- Administração endovenosa de Gluconato de cálcio 10\%, na dose de 0,5-1,5 $\mathrm{ml} / \mathrm{kg}$ para estabilização da condução cardíaca; administrado por 5 a 10 minutos associado à monitorização do eletrocardiograma;

- Administração endovenosa de solução eletrolítica balanceada para reidratação, diluição de potássio extracelular e restauração do equilibrio ácido-base;

- Bolus endovenoso de uma dose de insulina de ação curta, como insulina regular 0,5 U/kg, associada a um bolus de dextrose a $25 \%$ a $2 \mathrm{~g} / \mathrm{U}$ de insulina administrada; para captação intracelular de potássio. Após os bolus iniciais de insulina e dextrose, a dextrose pode ser continuada como infusão contínua.

O reestabelecimento da patência uretral tem início após estabilização do paciente. A escolha entre sedação e anestesia e os protocolos medicamentosos empregados variará conforme a condição do paciente e da experiência do clínico uretral (Scherk, 2015).

Para cateterização urinária, pode ser necessária sedação; butorfanol 0,1-0,2 mg / kg (IM ou IV) sozinho pode ser suficiente, porém, pode ser necessária sedação adicional ou anestesia geral. Um bloqueio peridural sacrococcígeo com um agente anestésico local é fácil de executar e altamente recomendado para fornecer analgesia e aumentar o sucesso do cateterismo uretral (Robertson et al., 2018).

Uma associação comumente empregada consiste em quetamina (2 a $5 \mathrm{mg} / \mathrm{kg})$ e diazepam $(0,2$ a $0,5 \mathrm{mg} / \mathrm{kg}$ ) ou midazolam $(0,2 \mathrm{a} 0,5 \mathrm{mg} / \mathrm{kg})$ administrados por via intravenosa. Contudo, a quetamina deve ser evitada em gatos com arritmias cardíacas ou com doença cardíaca. Hidromorfona e midazolam são outras escolhas comuns. A indução por máscara com isoflurano ou proporfol IV pode ser usada se houver necessidade de tempo adicional para procedimentos (Scherk, 2015).

Em alguns pacientes, a cistocentese percutânea pode ser realizada às cegas ou guiada por ultrassom para drenar a urina e reduzir o desconforto do paciente, embora a lesão na bexiga e a ruptura e laceração aórtica sejam possíveis complicações (Clark-Price \& Grauer, 2015).

\section{Particularidades Relacionadas aos Fármacos Utilizados na Anestesia}

\subsection{Medicação pré-anestésica (MPA)}

A pré-medicação antes da anestesia geral é parte do planejamento anestésico e deve ser personalizada para cada gato, levando em consideração o procedimento a ser realizado (Robertson et al., 2018). A pré-medicação tem como objetivo produzir um ou vários efeitos, por meio da administração de um único fármaco ou, associação destes (Pypendop \& Ilkiw, 2015). Os principais objetivos da pré-medicação são:

- Sedação para facilitar cateterismo intravenoso (IV) e indução anestésica;

- $\quad$ Redução de estresse e ansiedade;

- Analgesia;

- Redução da dose anestésica para indução e manutenção, a fim de reduzir efeitos adversos dos agentes anestésicos;

- Prevenção ou tratamento de efeitos adversos de outros fármacos administrados na pré-medicação, indução anestésica ou manutenção; 
- Melhora da qualidade da indução anestésica e/ou recuperação.

Os opioides são úteis tanto para MPA como parte de protocolos de sedação (Robertson et al., 2018). Nos gatos, os opioides causam dilatação pupilar e, às vezes, excitação. A excitação induzida por opioides geralmente é observada apenas após administração de doses altas; em doses clínicas, causam analgesia e euforia, às vezes disforia (Pascoe \& Pypendop, 2015).

Em doses baixas, o uso de opioides na MPA leva a discreta redução na frequência cardíaca. Anticolinérgicos podem ser usados para reverter esse efeito, se necessário. A atropina $(0,02 \mathrm{mg} / \mathrm{kg})$ e o glicopirrolato $(0,01 \mathrm{mg} / \mathrm{kg}) \mathrm{SC}$ podem aumentar a frequência cardíaca em cerca de 10\% em combinação com um opioide (Robertson et al., 2018).

Os opioides diminuem a dose de anestésico inalante necessária para produzir imobilidade em gatos. No entanto, a magnitude do efeito parece ser menor em gatos do que em outras espécies (Pascoe \& Pypendop, 2015).

Gatos tratados com acepromazina mostram-se sedados na ausência de estimulação, porém os efeitos parecem desaparecer com o manuseio. A acepromazina agrava o efeito hipotensivo de anestésicos inalantes em gatos, podendo dificultar o tratamento da hipotensão intraoperatória e alguns autores não utilizam comumente esse medicamento em felinos (Pypendop \& Ilkiw, 2015). A acepromazina não deve ser utilizada em face de hipotensão, hipovolemia ou desidratação préexistentes (Robertson et al., 2018).

Apesar disso, a acepromazina ainda é amplamente utilizada, muitas vezes combinado com outras drogas, como os opioides. As doses recomendadas variam de 0,01 a $0,05 \mathrm{mg} / \mathrm{kg}$ (SC ou IM); o tempo para atingir o pico da sedação pode ser de 20 a 30 minutos e os efeitos duram de 4 a 6 horas (Robertson et al., 2018).

Clinicamente, os benzodiazepínicos são, em algumas ocasiões, usados como pré-medicação antes da anestesia geral, associados a opioides, na tentativa de melhorar a sedação ocasionada por opioide (Pypendop \& Ilkiw, 2015). Entretanto, os benzodiazepínicos não parecem ser fármacos adequados para pré-medicação isoladamente ou em combinação com opioides em gatos jovens ou adultos saudáveis, devido a resultados não confiáveis, incluindo excitação e disforia; em pacientes geriátricos ou muito doentes, os benzodiazepínicos podem produzir sedação mais confiável (Robertson et al., 2018).

Os agonistas $\alpha 2$-adrenérgicos têm sido amplamente utilizados em gatos. Atualmente, os agentes mais usados nesta classe são medetomidina e dexmedetomidina (Robertson et al., 2018).

Em felinos os agonistas $\alpha 2$ proporcionam sedação confiável e redução da necessidade de anestésicos de forma dosedependente, além de analgesia. Contudo, a duração do efeito analgésico tanto da xilazina quanto da dexmedetomidina é curta (Pypendop \& Ilkiw, 2015).

Os efeitos cardiovasculares do fármaco incluem vasoconstrição, diminuição da frequência e débito cardíaco, aumento da resistência vascular sistêmica com alteração mínima da pressão arterial (Robertson et al., 2018). Os efeitos cardiovasculares devem ser usados com cautela em pacientes geriátricos ou com disfunção significativa de órgãos. Foi sugerido que o uso de medetomidina em gatos com miocardiopatia hipertrófica e obstrução ao fluxo ventricular esquerdo diminui a obstrução; espera-se que dexmedetomidina produz efeitos similares (Pypendop \& Ilkiw, 2015).

Muitos gatos que recebem doses elevadas de dexmedetomidina, apresentam vômito como efeito colateral. A combinação de dexmedetomidina com ondansetrona ou butorfanol reduz a incidência de vômitos, assim como o pré-tratamento com maropitant (Robertson et al., 2018). 


\subsection{Indução}

Os agentes anestésicos injetáveis disponíveis atualmente para induzir anestesia em gatos são: quetamina; mistura de tiletamina e zolazepam; tiopental; propofol; e etomidato. A alfaxalona está disponível apenas em alguns países; e o etomidato costuma ser utilizado apenas em pacientes idosos ou com comorbidades (Pypendop \& Ilkiw, 2015).

A indução anestésica pode ser obtida pela administração de fármacos injetáveis pelas vias SC, IM, IV ou por indução com anestésicos inalantes, utilizando câmara ou máscara. Em gatos, as vias IM e SC são as mais utilizadas, visto eu muitos pacientes não permitem cateterização endovenosa (Robertson et al., 2018).

Todos os medicamentos de indução possuem potencial efeito depressor do sistema respiratório; portanto, a préoxigenação deve ser uma prática padrão nos gatos (Robertson et al., 2018). Outro fator que deve ser levado em consideração nos felinos é o metabolismo do propofol. A depuração corporal total do propofol foi relatada como sendo pelo menos duas vezes mais lenta do que em cães, isso porque, o propofol é metabolizado através da glucuronidação (Pascoe \& Pypendop, 2015).

É importante ressaltar que na maioria dos fármacos indutores, existe a possibilidade de excitação com doses baixas, portanto o bolus inicial deve ser grande o suficiente para evitar esse efeito, mas pequeno o suficiente para minimizar eventos cardiopulmonares adversos (Robertson et al., 2018).

\subsection{Manutenção}

Os anestésicos inalatórios são bastante utilizados para a manutenção de anestesia em gatos. Permitem ajuste previsível e rápido da profundidade anestésica, e possibilitam recuperação rápida evitando metabolização e excreção de fármacos pelo fígado ou pelos rins. O oxigênio concomitantemente, e a ventilação pode ser facilmente controlada quando necessário. Dos anestésicos inalatórios disponíveis para uso em gatos, apenas o isoflurano e o sevoflurano são utilizados rotineiramente na clínica veterinária (Pypendop \& Ilkiw, 2015).

A dose dos anestésicos inalatórios é maior em gatos do que em outras espécies. O isoflurano e o sevoflurano têm efeitos profundos no sistema cardiovascular, com o débito cardíaco e a pressão arterial diminuindo de 50 a $70 \%$ nas concentrações necessárias para a cirurgia. Contudo, esse efeito é parcialmente revertido por estímulos nocivos, como incisões cirúrgicas, por exemplo, fazendo com que os efeitos não sejam notados (Robertson et al., 2018).

Efeitos benéficos do uso de infusão de opioides foram frequentemente relatados em gatos. A administração da infusão associada a anestesia inalatória, possibilita redução na concentração dos agentes inalatórios, com efeitos mínimos no sistema cardiovascular (Pypendop \& Ilkiw, 2015; Robertson et al., 2018).

Além dos opioides, a lidocaína e a quetamina também tem sido administradas via infusão contínua buscando potencializar a analgesia e reduzir a concentração alveolar mínima (CAM) dos agentes inalatórios durante a manutenção anestésica (Kushner, 2010b; Pypendop \& Ilkiw, 2015; Robertson et al., 2018).

A lidocaína IV pode ser administrada a gatos em infusões contínuas para analgesia e redução da CAM, embora documentada a eficácia é variável e questionável (Kushner, 2010b). Entretanto, estudos cardiovasculares demonstraram que o decréscimo das necessidades inalatórias esteve associado a maior depressão cardiovascular (Pypendop \& Ilkiw, 2015).

Apesar de não ter sido avaliada em gatos, a mistura de morfina, lidocaína e morfina (MLK) tornou-se uma técnica anestésica balanceada muito comum na clínica veterinária, sendo disseminada para uso para gatos, embora alguns clínicos não adicionem lidocaína na solução (Pypendop \& Ilkiw, 2015).

O propofol têm sido utilizados para anestesia intravenosa total em gatos. Como o propofol é conjugado no fígado via glucuronidação, o tempo de recuperação varia de acordo com a dose e a duração da infusão. Recomenda-se o uso de doses baixas (0,1-0,15 mg / kg / min), limitando o período de infusões de propofol a menos de 30 minutos (Robertson et al., 2018). 
Em estudo realizado por Bley e colaboradores (2007), os resultados indicaram que a anestesia de curta duração associada a doses repetidas de propofol não leva a alterações hematológicas clinicamente relevantes em gatos.

Embora o propofol contendo álcool benzílico a $2 \%$ seja seguro e apropriado para indução da anestesia em gatos, esta fórmula não deve ser usada como infusão devido ao potencial de acúmulo de álcool benzílico (Robertson et al., 2018).

\section{Considerações Adicionais}

\subsection{Manejo das vias aéreas}

O manejo adequado das vias aéreas é essencial para a anestesia segura em gatos. A anestesia geral está associada à perda de reflexos protetores das vias aéreas e depressão respiratória. Portanto, é importante manter uma via aérea patente, para impedir a aspiração e poder fornecer oxigênio e anestésicos inalantes e apoiar a ventilação quando necessário (Mosley, 2015; Robertson et al., 2018).

Tanto em felinos como em humanos há um grande risco de complicações graves, incluindo óbito, devido ao manejo das vias aéreas (Brodbelt, et al., 2007). As principais complicações respiratórias incluem problemas com manutenção das vias aéreas e inadequação da ventilação, falha na intubação endotraqueal, trauma nas vias aéreas superiores e ventilação inadequada (Brodbelt, 2010).

Tubos endotraqueais são comumente utilizados para manutenção das vias aéreas em pacientes anestesiados. Um tubo endotraqueal com o cuff inflado fornece uma via aérea patente, facilita a ventilação com pressão positiva, protege os pulmões da aspiração de fluidos e evita a contaminação do ambiente com gases anestésicos utilizados (Mosley, 2015). Embora todos esses fatores sejam vantagens importantes, problemas de intubação endotraqueal e obstrução respiratória representam uma causa importante de morte em gatos (Clarke \& Hall,1990; Dyson et al., 1998) correlacionando-se ao aumento do risco anestésico (Brodbelt et al., 2007; Brodbelt, 2010). Por isso, há necessidade de cuidados extras durante a intubação endotraqueal nessa espécie (Pypendop \& Ilkiw, 2015).

Em estudo realizado por Brodbelt e colaboradores (2007), mais casos que foram intubados vieram a óbito no período pós-operatório do que aqueles que não foram (63\% dos gatos que morreram tiveram intubação endotraqueal em comparação com $48 \%$ dos gatos não intubados). Além disso, os autores sugeriram que trauma laríngeo, espasmo ou edema tenham contribuído mais nos casos de óbito do que a obstrução do tubo endotraqueal.

Em outro estudo, a intubação foi associada a um risco aumentado de complicações em gatos, com dez por cento das complicações associadas à intubação. Contudo, os mesmos autores sugerem que mesmo com o aumento do risco, ela não deve ser evitada em gatos se a duração ou o tipo de procedimento justificar, e em casos de procedimentos de curta duração, onde técnica de anestesia injetável está sendo utilizada, a monitorização da ventilação espontânea e estar preparado para intubar e pode ser suficiente (Dyson et al., 1998).

Complicações mais graves também foram relatadas, em estudo realizado por Clarke e Hall (1990), a intubação endotraqueal resultou em ruptura traqueal em um gato e outro veio a óbito no período pós-operatório por inalação do tubo endotraqueal. Trauma devido à dificuldade de intubação ou após permanência do tubo endotraqueal em posição durante a recuperação anestésica foram associados a quatro casos de obstrução das vias aéreas neste estudo.

As razões para associação de complicações anestésicas com a intubação traqueal em felinos não são totalmente claras; no entanto, acredita-se que haja correlação com o pequeno tamanho das vias aéreas superiores do gato e à sua resposta laríngea à estimulação mecânica; uma vez que o espasmo da laringe pode ser produzido em gatos anestesiados e descerebrados por estimulação mecânica do palato mole, faringe, laringe e traqueia (Pascoe \& Pypendop, 2015). 
Na prática, a intubação é frequentemente usada em cães e, em menor grau, em gatos. As taxas mais baixas de intubação em gatos têm sido atribuídas a procedimentos curtos, a dificuldade relativamente maior da intubação endotraqueal e possivelmente a associação com aumento da mortalidade descrita anteriormente (Sano et al., 2017).

A via aérea felina é pequena e mais sensível a traumas, espasmos e edemas comparativamente a do cão ou do cavalo, dessa forma, o processo de intubação, se não for realizado adequadamente, pode aumentar o risco de complicações. Sugere-se então, que a intubação endotraqueal seja realizada com especial cuidado em gatos, porém, o fornecimento de uma via aérea patente (via colocação de um tubo endotraqueal) permanece importante (Brodbelt, 2010).

Outra recomendação importante em gatos é a dessensibilização da laringe com um anestésico local antes da intubação, a fim de diminuir a incidência de espasmo laríngeo (Pypendop \& Ilkiw, 2015; Pascoe \& Pypendop, 2015).

As diretrizes mais recentemente publicadas pela AAFP (Robertson et al., 2018), traz a sequência ideal para intubação adequada dos felinos:

- Se o gato for tolerante, pré-oxigenar por 3 minutos usando uma máscara facial ou técnica de escoamento (mangueira de oxigênio); administre o medicamento de indução; posicione o gato em decúbito esternal e verifique se há relaxamento muscular geral e o tônus da mandíbula. Identifique as cartilagens aritenóides e as pregas vocais; utilizando uma seringa de $1 \mathrm{ml}$, coloque $\pm 0,2 \mathrm{ml}$ de lidocaína nas aritenóides, evitando contato da seringa com as estruturas, e aguarde 60-90 s. Mantenha a ponta do tubo endotraqueal próxima à abertura glótica, com a parte mais distal da ponta na vertical, e avance o tubo suavemente; se o paciente tossir ou resistir, pare e administre um agente de indução adicional. Se ocorrer laringoespasmo, pare e administre oxigênio. Avalie a profundidade da anestesia e administre agente de indução adicional, se necessário. A reaplicação da lidocaína pode ser considerada, assegurando-se de que seja feita 60 a 90 s antes de nova tentativa de intubação.

Os dispositivos supraglóticos das vias aéreas, também conhecidos como máscaras laríngeas, estão se tornando cada vez mais populares para uso veterinário. No mercado, existe modelo específico para uso veterinário (v - gel $\AA$, Docsinnovent Ltd, Londres, Reino Unido), projetado para uso em gatos e coelhos. Esses dispositivos são uma alternativa à intubação endotraqueal para manutenção de uma via aérea patente, e há algumas evidências de que podem ser mais simples e rápidos do que os tubos endotraqueais em algumas espécies, como gatos e coelhos (Mosley, 2015).

Entre as vantagens da utilização da máscara laríngea, incluem menor requerimento de propofol do que a intubação endotraqueal, portanto, a depressão cardiorrespiratória induzida por propofol é provavelmente menos grave, além de serem menos invasivos, pois não requerem o uso de laringoscópio e não entram na laringe ou traqueia (Wiederstein, Auer \& Moens, 2006).

Outras vantagens desse sistema, são a redução do desconforto e do estridor nas vias aéreas superiores; e a maior ingestão de alimentos no período de recuperação dos gatos (Robertson et al., 2018).

Além disso, o tempo para obter uma avaliação clínica e a leitura aceitável do capnógrafo foi mais curta quando a máscara laríngea foi usada em comparação com o uso de tubo endotraqueal (Robertson et al., 2018).

\subsection{Termorregulação perioperatória e balanço de calor}

Aumento ou redução da temperatura corporal são frequentemente encontrados em animais durante anestesia. Hipertermia pode ser causada por estresse, aumentos na atividade muscular (relaxamento inadequado), doença sistêmica e / ou distúrbios infecciosos e genéticos (hipertermia maligna). Já a hipotermia é uma consequência comum da anestesia e cirurgia (Grimm, 2015). 
A hipotermia durante a anestesia pode estar associada ao anestésico depressão de drogas da atividade muscular, metabolismo e mecanismos termostáticos hipotalâmicos (Lenhardt, 2003; Haskins, 2015). Procedimento e fatores ambientais também promovem a perda de calor, como excesso de umidade (por exemplo, durante procedimentos odontológicos), uma cavidade corporal aberta, contato com superfícies frias, exposição a ambiente frio, comorbidades (choque), medicamentos que causam vasodilatação (fenotiazínicos, anestesia inalatória) e relaxantes musculares (bloqueadores neuromusculares) (Grimm, 2015; Robertson et al., 2018).

A hipotermia durante a anestesia pode estar associada ao anestésico depressão de drogas da atividade muscular, metabolismo e hipotalâmico mecanismos termostáticos. A perda de calor pode ser aumentada pela evaporação das soluções cirúrgicas da superfície da pele, pela infusão de fluidos em temperatura ambiente, por contato com superfícies frias e não isoladas e por evaporação do fluido de superfície de uma cavidade corporal exposta.

A hipotermia perianestésica inadvertida é uma das complicações mais comuns na anestesia de cães e gatos; podendo resultar em alterações na farmacocinética dos medicamentos anestésicos e analgésicos, disfunção dos sistemas orgânicos, aumento da suscetibilidade do paciente à infecção, redução da cicatrização de feridas, coagulação alterada, hipotensão e recuperação tardia (Clark-Price, 2015; Norsworthy \& Romeo, 2018; Robertson et al., 2018).

Alterações na temperatura corporal também afetam a concentração do íon $\mathrm{H}+$ de todos os fluidos corporais. Os aumentos na temperatura corporal diminuem o $\mathrm{pH}$ (aumentam $[\mathrm{H}+])$ e vice-versa, de modo que o $\mathrm{pH}$ do sangue mude de 0,015 a 0,02 unidades $/{ }^{\circ} \mathrm{C}$ (Grimm, 2015).

A hipotermia é muito mais observada em pequenos animais ( $<8$ a $10 \mathrm{~kg}$ ), devido à maior proporção superfície/volume corporal. Dessa forma, os gatos estão sujeitos a essa alteração de forma mais acentuada (Clark-Price, 2015; Grimm, 2015; Robertson et al., 2018).

O músculo pode atuar como centro de geração de calor e a gordura funciona como isolamento subcutâneo para reduzir o corpo perda de calor. Como é de se esperar, animais caquexicos e extremamente magros correm maior risco de desenvolver hipotermia (Clark-Price, 2015).

De forma geral, a hipotermia ocorre mais comumente em gatos com baixo escore de condição corporal; que estão sob anestesia por mais de 30 minutos; que apresentam uma doença sistêmica importante ou que tiveram a cavidade abdominal acessada, principalmente com exteriorização das vísceras (Norsworthy \& Romeo, 2018).

Muitos pacientes cirúrgicos felinos têm todos esses fatores de risco. Dessa forma, queda significativa da temperatura corporal é quase inevitável durante uma laparotomia, portanto, o tratamento da hipotermia é baseado em uma combinação de medidas preventivas e corretivas (Norsworthy \& Romeo, 2018).

Como o método mais eficaz para prevenir a perda de calor é aumentar a temperatura ambiente ou cercar o animal com um ambiente quente, os métodos para manter a temperatura corporal devem ser iniciados na área de espera do paciente antes da pré-medicação e continuados durante a anestesia e recuperação (Robertson et al., 2018).

Os métodos de calor externo possibilitam que a temperatura seja controlada para impedir o risco de queimaduras cutâneas. Cobertores com água aquecida circulante são usados com frequência, mas eles são limitados, por causa da área limitada disponível para troca de calor com o paciente. Os sistemas de ar são mais usados.122 Quando esses sistemas são usados, deve-se ter cuidado para não causar hipertermia (Pypendop \& Ilkiw, 2015).

Manter a temperatura corporal central usando uma abordagem de aquecimento ativo, como dispositivos de ar quente forçado e cobertores elétricos e de água quente circulantes, será mais eficaz do que os métodos passivos de manutenção da temperatura (cobertores, e etc.). Quando esses sistemas são usados, deve-se ter cuidado para não causar hipertermia (Pypendop \& Ilkiw, 2015). Usar soluções aquecidas, limitar o campo cirúrgico e manter o paciente seco também são importantes (Robertson et a., 2018). 
Os custos térmicos da fluidoterapia e dos gases frios e secos do circuito respiratório são pequenos, mas o fornecimento de fluido aquecida pode diminuir a perda de calor (Robertson et al., 2018).

Para avaliar a hipotermia perianestésica, a temperatura central deve ser monitorada vigorosamente (Lenhardt, 2003). A aferição da temperatura central pode ser feita com termômetro esofágicos ou retais conectados a um monitor com exibição contínua (Haskins, 2015).

\subsection{Considerações Finais}

A revisão do presente estudo, permite afirmar que atenção especial deve ser dispensada aos gatos, visto que esses pacientes têm maior risco de morte relacionada a procedimentos anestésicos, especialmente devido ao grande número de particularidades da espécie. Dessa forma, uma avaliação pré-operatória mais cuidadosa, conjuntamente a preparação e modificação das práticas anestésicas podem auxiliar na redução da mortalidade. Além disso, o gerenciamento anestésico bemsucedido requer membros treinados da equipe que conheçam as particularidades e as adaptações fisiológicas do paciente felino submetido a procedimentos anestésicos.

\section{Referências}

Adami, C., Di Palma, S., Gendron, K., \& Sigrist, N. (2011). Severe esophageal injuries occurring after general anesthesia in two cats: case report and literature review. J Am Anim Hosp Assoc, 47(6), 436-442. https://pubmed.ncbi.nlm.nih.gov/22058351.

Adams, J.G., Figueiredo, J. P., \& Graves, T.K. (2015). Physiology, Pathophysiology, and Anesthetic Management of Patients with Gastrointestinal and Endocrine Disease. In: Lumb \& Jones. Veterinary Anesthesia and Analgesia. (5a ed.), Ames, Iowa: Blackwell Publishing.

American Veterinary Medical Association (AVMA). (2018). AVMA Pet Ownership \& Demographics Sourcebook. https://www.avma.org/sites/default/files/resources/AVMA-Pet-Demographics-Executive-Summary.pdf.

Bednarski, R., Grimm, K., Harvey, R., Lukasik, V. M., Penn, W. S., Sargent, B., \& Spelts, K. (2011). AAHA anesthesia guidelines for dogs and cats. J Am Anim Hosp Assoc, 47(6), 377-385. https://www.aaha.org/globalassets/ 02guidelines/anesthesia/anesthesia_guidelines_for_dogs_and_cats.pdf.

Bley, C. R., Roos, M., Price J., Ruess-Melzer, K., Buchholz, J., Poirier, V., \& Kaser-Hotz B. (2007). Clinical assessment of repeated propofol-associated anesthesia in cats. J Am Vet Med Assoc, 231(9), 1347-1353. https://pubmed.ncbi.nlm.nih.gov/17975992/.

Brodbelt, D. (2010). Feline anesthetic deaths in veterinary practice. Top Companion Anim Med, 25(4), 189-194. https://pubmed.ncbi.nlm.nih.gov/21147471.

Brodbelt, D. C., Pfeiffer, D. U., Young, L. E., \& Wood, J. L. (2007). Risk factors for anaesthetic-related death in cats: results from the confidential enquiry into perioperative small animal fatalities (CEPSAF). Br J Anaesth, 99(5), 617-623.

Clarke, K. W., \& Hall, L. W. (1990). A survey of anaesthesia in small animal practice: AVA/BSAVA report. J. Ass. vet. Anaesth, 17(1), 4 - 10. https://onlinelibrary.wiley.com/doi/abs/10.1111/j.1467-2995.1990.tb00 380.x.

Clark-Price, S. (2015). Inadvertent perianesthetic hypothermia in small animal patients. Vet Clin North Am Small Anim Pract, 45(1), 983-994. https://pubmed.ncbi.nlm.nih.gov/26014270/.

Clark-Price, S. C., \& Grauer, G. F. (2015). Physiology, Pathophysiology, and Anesthetic Management of Patients with Renal Disease. In: Lumb \& Jones. Veterinary Anesthesia and Analgesia. (5a ed.), Ames, Iowa: Blackwell Publishing.

Davis, H., Jensen, T., Johnson, A., Knowles, P., Meyer, R., Rucinsky, R., \& Shafford, H. (2013) AAHA/AAFP fluid therapy guidelines for dogs and cats. $J$ Am Anim Hosp Assoc, 49(3), 149-159. https://pubmed.ncbi.nlm.nih.gov/23645543.

Dyson, D. H., Maxie, M. G., \& Schnurr, D. (1998). Morbidity and mortality associated with anesthetic management in small animal veterinary practice in Ontario. J Am Anim Hosp Assoc, 34(4): 325-335.

Galatos, A. D., \& Raptopoulos, D. (1995). Gastro-oesophageal reflux during anaesthesia in the dog: the effect of preoperative fasting and premedication. Vet Rec, 137(19), 479-83. https://pubmed.ncbi.nlm.nih.gov/8578660.

Garcia, R. S., Belafsky, P. C., Della Maggiore, A., Osborn, J. M., Pypendop, B. H., Pierce, T., Walker, V. J., Fulton, A., \& Marks, S. L. (2007). Prevalence of Gastroesophageal Reflux in Cats During Anesthesia and Effect of Omeprazole on Gastric pH. Journal of veterinary internal medicine, 31(3), 734-742.

Gil-Ortuño, C., Sebastián-Marcos, P., Sabater-Molina, M., Nicolas-Rocamora, E., Gimeno-Blanes, J. R., \& Del Palacio, M. J. F. (2020). Genetics of feline hypertrophic cardiomyopathy. An International Jornaul of Genettics, Molecular and Personalized Medicine, 86(3), $203-214$.

Grimm, K. A. (2015). Perioperative Thermoregulation and Heat Balance. In: Lumb \& Jones. Veterinary Anesthesia and Analgesia. (5a ed.), Ames, Iowa: Blackwell Publishing. 
Grubb, T., Sager, J., Gaynor, J. S., Montgomery, E., Parker, J. A., Shafford, H., \& Tearney, C. (2020) AAHA. Anesthesia and Monitoring Guidelines for Dogs and Cats. J Am Anim Hosp Assoc, 56(2), 59-82.

Hashim, M. A., \& Waterman, A. E. (1991). Effects of thiopentone, propofol, alphaxalone-alphadolone, ketamine and xylazine-ketamine on lower oesophageal sphincter pressure and barrier pressure in cats. Vet Rec, 129 (7), 137-139.

Haskins, S. C. (2015). Monitoring Anesthetized Patients. In: Lumb \& Jones. Veterinary Anesthesia and Analgesia. (5a ed.), Blackwell Publishing.

Horwitz, D. F., \& Pike, A. L. (2018). Aggression, Human Directed. In: Norsworthy, G. D. The Feline Patient. (5a ed.), Wiley.

Hosgood, G., \& Scholl, D. T. (2002). Evaluation of age and American Society of Anesthesiologists (ASA) physical status as risk factors for perianesthetic morbidity and mortality in the cat. Journal of Veterinary Emergency and Critical Care, 12(1), $9-16$.

Kim, J. H., Byun, S., Choi, Y. J., Kwon, H. J., Jung, K., Kim, S. E., Park, M., Moon, W., \& Park, S. J. (2020). Efficacy and Safety of Etomidate in Comparison with Propofol or Midazolam as Sedative for Upper Gastrointestinal Endoscopy. Clinical Endoscopy, 53(5), 555-561.

Kushner, L. I. (2010a). Guidelines for anesthesia in critically ill feline patients. In: Drobatz, K. J., \& Costello, M. F. Feline Emergency and Critical Care Medicine. Blackwell Publishing.

Kushner, L. I. (2010b). Anesthetic protocols for systemically healthy cats. In: Drobatz, K.J., \& Costello, M.F. Feline Emergency and Critical Care Medicine. Blackwell Publishing.

Lamont, L. A., Bulmer, B. J., Sisson, D. D., Grimm, K. A., \& Tranquilli, W. J. (2002). Doppler echocardiographic effects of medetomidine on dynamic left ventricular outflow tract obstruction in cats. J Am Vet Med Assoc, 221(9), 1276-1281.

Lenhardt, R. (2003). Monitoring and thermal management. Best Pract Res Clin Anaesthesiol, 17(4), 569-581. https://pubmed.ncbi.nlm.nih.gov/14661658.

Marino, C. L., Lascelles, B. D., Vaden, S. L., Gruen, M. E., \& Marks, S. L. (2014). Prevalence and classification of chronic kidney disease in cats randomly selected from four age groups and in cats recruited for degenerative joint disease studies. J Feline Med Surg, 16(6), 465-472.

Mcdonell, W. N., \& Kerr, C. L. (2015). Physiology, Pathophysiology, and Anesthetic Management of Patients with Respiratory Disease. In: Lumb \& Jones. Veterinary Anesthesia and Analgesia. (5a ed.), Blackwell Publishing.

Mosley, C. A. (2015). Anesthesia Equipment. In: Lumb \& Jones. Veterinary Anesthesia and Analgesia. (5a ed.), Blackwell Publishing.

Murphy, M., Bartges, J., Kirk, C., Witzel, L. A., Hamper, B., \& Raditic, D. (2015). Controvérsias sobre a Nutrição de Felinos. In: Little, S. E. $O$ Gato: Medicina Interna. Guanabara Koogan.

Norsworthy, G. D., \& Romeo, A. (2018). Hypothermia, Surgical. In: Norsworthy, G. D. The Feline Patient. (5a ed.), Wiley.

Pascoe, P. J., \& Pypendop, B. H. (2015). Comparative Anesthesia and Analgesia of Dogs and Cats. In: Lumb \& Jones. Veterinary Anesthesia and Analgesia. (5a ed.), Blackwell Publishing.

Pereira, A. S., Shitsuka, D. M., Pereira, F. J., \& Shitsuka, R. (2018). Como Escrever um Artigo Ciêntífico. Metodologia da Pesquisa Científica. UFSM.

Perkowski, S. Z., \& Oyama, M. A. (1984). Pathophysiology and Anesthetic Management Peterson, M.E., Birchard, S.J., \& Mehlhaff, C.J. Anesthetic and surgical management of endocrine disorders. Vet Clin North Am Small Anim Pract, 14(4), 911-925.

Peterson, M. E., Ferguson, D. C., Kintzer, P. P., \& Drucker, W. D. (1984). Effects of spontaneous hyperadrenocorticism on serum thyroid hormone concentrations in the dog. American Journal of Veterinary Research, 45(10):2034-2038.

Pypendop, B. H., \& Ilkiw, J. E. (2015). Anestesia e Cuidados Pericirúrgicos. In: Little, S. E. O Gato: Medicina Interna. Guanabara Koogan.

Quimby, J., \& Lappin, M. R. (2015). Medicina Respiratória e Torácica. In: Little, S. E. O Gato: Medicina Interna. Guanabara Koogan.

Robertson, S. A., Gogolski, S.M., Pascoe, P., Shafford, H. L., Sager, J., \& Griffenhagen, G. M. (2018). AAFP Feline Anesthesia Guidelines. J Feline Med Surg, 20(7), 602-634. https://pubmed.ncbi.nlm.nih.gov/29989502/.

Rodan, L., Sundahl, E., Carney, H., Gagnon, A.C., Heath, S., Landsberg, G., Seksel, K., \& Yin, S. (2011). AAFP and ISFM feline friendly handling guidelines. J Feline Med Surg, 13(1), 364-375. https://pubmed.ncbi.nlm.nih.gov/21515223/.

Sano, H., Barker, K., Odom, T., Lewis, K., Giordano, P., Walsh, V., \& Chambers, J. P. (2017). A survey of dog and cat anaesthesia in a sample of veterinary practices in New Zealand. New Zealand Veterinary Journal, 66(2), 85-92.

Scherk, M. (2015). Distúrbios do Trato Urinário. In: Little, S. E. O Gato: Medicina Interna. Guanabara Koogan.

Serafini, C. A., Rosa, G. A., Guimaraes, A. M., De Morais, H. A., \& Biondo, A. W. (2008). Survey of owned feline and canine populations in apartments from a neighbourhood in Curitiba, Brazil. Zoonoses Public Health, 55(1), 8-10, 402-405.

Toribio, J. A., Norris, J. M., White, J. D., Dhand, N. K., Hamilton, S. A., \& Malik, R. (2009). Demographics and husbandry of pet cats living in Sydney, Australia: results of cross-sectional survey of pet ownership. J Feline Med Surg, 11(6), 9-461.

Wiederstein, I., Auer, U., \& Moens, Y. (2006). Laryngeal mask airway insertion requires less propofol than endotracheal intubation in dogs. Vet Anaesth Analg, 33(4), 201-206. https://pubmed.ncbi.nlm.nih.gov/16764583. 